\title{
Seletividade de inseticidas a alguns dos inimigos naturais na cultura do algodão
}

\section{Selectivity of insecticides to some natural enemies in the culture of cotton}

\author{
Elizio Pereira Diamantino', Maria Aparecida Castellani ${ }^{2 *}$, Luiz Carlos Forti ${ }^{3}$, \\ Aldenise Alves Moreira², Alcebíades Rebouças São Joséz ${ }^{2}$ Juliana Alves de Macedo 4 , \\ Fabiano de Sousa Oliveira ${ }^{4}$, Bruna Santos Silva ${ }^{4}$
}

| | | | | | | | | | | | | | | | | | | | | | | | | | | | | | | | | | | | | | | | | | | | | | | | | | | | | | | | | | | | | | | | | | | | | | | | | | | | | | | | | | | | | | | | | | | | | | | | | | | | | | | | | | | | | | | | | | | | | | | | | | | | | | | | | | | | | | | | | | | | | | | | | | | | | | | | | | | | | | | | | | | | | | | | | | | | | | | | | | | | | | | | | | | | | | | | | | | | | | | |

RESUMO: O objetivo foi estudar a seletividade de inseticidas aos inimigos naturais na cultura do algodão (Gossypium hirsutum L.r. latifolium Hurtch), cultivar DeltaOpal, no município de Malhada (BA) e conhecer a fauna benéfica associada. O trabalho foi conduzido na safra 2010/2011, com delineamento experimental em blocos ao acaso, com seis tratamentos e quatro repetiçôes, sendo os tratamentos: (1) Fipronil 200 SC (0,38 L.ha-1); (2) Alfacipermetrina 100 SC (0,30 L.ha-1); (3) Lufenuron 50 CE $\left(0,30{\mathrm{~L} . \mathrm{ha}^{-1}}^{-1}\right.$; (4) Imidacloprid $200 \mathrm{SC}$ $\left(0,30\right.$ L.ha $\left.^{-1}\right)$; (5) Paration Metil 600 CE (1,00 L.ha $\left.{ }^{-1}\right)$; e (6) Testemunha (água). A aplicação dos produtos foi feita 80 dias após a emergência, com avaliaçóes um dia antes da aplicação e 1, 7 e 14 dias após a aplicação (DAA) por meio do pano de batida e armadilha Moericke. Em laboratório, os insetos foram triados, contados e identificados em famílias. A toxicidade dos produtos varia em função do grupo do inimigo natural. A Imidacloprida é seletiva às aranhas, sendo os demais inseticidas medianamente tóxicos (Alfacipermetrina e Paration Metil: $1^{\circ}$ e $14^{\circ}$ DAA; Lufenuron: 14 DAA) ou tóxicos (Fipronil e Alfacipermetrina: $\left.7^{\circ} \mathrm{DAA}\right)$. Fipronil (1 DAA), Alfacipermetrina (70 DAA) e Paration Metil (14\% DAA) são medianamente tóxicos aos adultos de joaninhas. Os inseticidas estudados são tóxicos às larvas de joaninhas, com mais impacto até os sete dias após a aplicação, com exceção do Paration Metil, classificado como inócuo até esse período. Registra-se a ocorrência de 13 famílias de aranhas e 18 famílias de hymenópteros parasitoides em agroecossistema de algodão na região de Malhada (BA).

PALAVRAS-CHAVE: controle biológico; controle químico; manejo integrado; parasitoides; predadores.

\begin{abstract}
The aim of this work was study the selectivity of insecticides in favor of natural enemies in cotton (Gossypium hirsutum latifolium Hurtch Lr), DeltaOpal cultivar, in the city of Malhada (BA), and to know the associated beneficial fauna. The study was conducted at the agricultural year of 2010/2011. The design was conducted in randomized blocks with six treatments and four replications. The treatments were: (1) Fipronil 200 SC (0.38 L.ha $\left.{ }^{-1}\right)$; (2) Alphacypermethrin 100 SC (0.30 L.ha $\left.{ }^{-1}\right)$, (3) Lufenuron 50 EC (0.30 L.ha $\left.{ }^{-1}\right)$, (4) Imidacloprid 200 SC (0.30 L.ha-1), (5) Methyl parathion $600 \mathrm{EC}\left(1.00 \mathrm{~L}^{-h^{-1}}\right)$, and (6) control (water). The product was applied 80 days after emergence, and the evaluations were performed one day before application and 1, 7 and 14 days after application (DAA). The samples were taken using the sampling method beating cloth and Moericke traps. Natural enemies were brought to the laboratory for sorting, counting and identification by family. The toxicity of the products ranged according to the group of natural enemies. Imidacloprid is selective to the spiders and insecticides are moderately toxic (Methyl Parathion and Alphacypermethrin: 1 and $14^{\text {th }}$ DAA; Lufenuron: $14^{\text {th }}$ DAA) or toxic (Fipronil and Alphacypermethrin: $7^{\text {th }}$ DAA). Fipronil (1 DAA), Alphacypermethrin ( $7^{\text {th }}$ DAA) and Methyl Parathion (14 ${ }^{\text {th }}$ DAA) are moderately toxic to adult ladybirds. The analyzed insecticides are toxic to the larvae of ladybirds, with more impact until seven days after the application, with the exception of Methyl Parathion classified, as innocuous until this period. The occurrence of 13 families of spiders and 18 families of parasitic Hymenoptera is registered in cotton agroecosystems in the region of Malhada, in the state of Bahia.
\end{abstract}

KEYWORDS: biological control; chemical control; integrated management; parasitoids; predators.

\footnotetext{
'Programa de Pós-Graduação em Agronomia; Universidade Estadual do Sudoeste da Bahia (UESB) - Vitória da Conquista (BA), Brasil. 2Departamento de Fitotecnia e Zootecnia; UESB - Vitória da Conquista (BA), Brasil.

${ }^{3}$ Faculdade de Ciências Agronômicas; Universidade Estadual “Júlio de Mesquita Filho" (UNESP) - Botucatu (SP), Brasil.

${ }^{4}$ Programa de Iniciação Científica; UESB - Vitória da Conquista (BA), Brasil.

*Autor correspondente: castellani.uesb@gmail.com

Recebido em: 07/12/2011. Aceito em: 06/01/2014.
} 


\section{INTRODUÇÃO}

O Brasil é um dos maiores produtores mundiais de algodão, ocupando a quinta colocação, e o quarto maior exportador, apresentando recorde histórico de área plantada: quase 1,4 milháo de hectares e produção de 1,96 milhão de toneladas em pluma na safra 2010/2011. No entanto, na safra 2012/2013 registrou-se queda de $37 \%$ em área plantada em relação à temporada de 2011/2012, caindo de 1.393 .739 hectares para 869.887 hectares na atual safra, ou seja, é um momento de ajuste na produção nacional. Os estados de Mato Grosso e Bahia são responsáveis por $83,2 \%$ da lavoura brasileira de algodáo, sendo a Bahia o segundo produtor nacional (REETZ et al., 2013), com destaque para a regiáo oeste do Estado, que responde por mais de $90 \%$ da produção.

A cultura do algodão hospeda várias espécies de artrópodes-pragas, o que exige o uso de inseticidas, muitas vezes, de forma irracional. Por outro lado, o agroecossistema dessa cultura é também rico em inimigos naturais, importantes agentes do controle biológico (Silva; Almeida, 1998). Apesar dos diversos métodos de controle que podem ser utilizados para supressão das pragas do algodoeiro, atualmente quase todos os sistemas de produçáo são dependentes do uso de inseticidas (Degrande, 1998), desconsiderando-se, na maioria das vezes, os efeitos adversos desses compostos nos artrópodes predadores e parasitoides, podendo ocasionar surtos de pragas secundárias, ressurgência e resistência das pragas aos inseticidas (CAmpos et al., 1986; Busoli, 1991), dentre outros impactos negativos.

Considerando os princípios do manejo integrado de pragas, as aplicaçôes de inseticidas devem ser feitas somente quando necessárias, e esta decisão foi tomada em função do nível de controle específico de cada inseto praga (Alves; Serikawa, 2006). O manejo integrado tem na seletividade de inseticidas um dos seus componentes básicos, permitindo a preservação dos inimigos naturais (СRосомо, 1990), cuja abundância e importância variam consideravelmente de ano a ano e de região a região (Gravena; Cunha, 1991; EVANGELISTA JúNIOR et al., 2006).

No Brasil, estudos em campo sobre a seletividade de inseticidas químicos e biológicos a inimigos naturais da cultura do algodáo têm sido desenvolvidos em diferentes regióes produtoras, com ênfase na ação dos produtos sobre predadores (NunES et al., 1999; Soares; Busoli, 2000; CzepaK et al., 2005; Lima Júnior et al., 2010, Suekane et al., 2011). Sáo escassos os trabalhos em campo que avaliam os impactos sobre parasitoides (Реrioto et al., 2001). Tais estudos englobam inseticidas registrados para a cultura há bastante tempo, como o endosulfan (Nunes et al., 1999; SOAREs; Busoli, 2000; CZEPAK et al., 2005), paration metil (FonseCA et al., 2008), dentre outros, bem como inseticidas dos grupos químicos dos neonicotinoides (Czepak et al., 2005) e fenil pirazóis (Soares; Busoli, 2000), de registro mais recente para a cultura, a exemplo dos princípios ativos imidacloprida e fipronil, respectivamente. Alguns estudos envolvem também inseticidas reguladores de crescimento dos insetos (Nunes et al., 1999). De modo geral, constata-se a variação na classificação dos inseticidas em função dos diferentes tipos de inimigos naturais, das metodologias de avaliação utilizadas, da formulação e regiōes estudadas, o que dificulta a recomendaçấo segura aos produtores de inseticidas seletivos nas diferentes regiôes de cultivo.

$\mathrm{Na}$ Bahia, o algodáo é plantado nas regiôes oeste e sudoeste, com manejos relativamente diferenciados, predominando um sistema empresarial no oeste e um familiar no sudoeste. No entanto, em ambas as regióes o uso de inseticidas é intenso, não havendo subsídios científicos que possam respaldar a recomendação de produtos seletivos aos inimigos naturais para as diferentes condiçóes edafoclimáticas e de sistema de cultivo. Recentemente, constatou-se a presença da praga Helicoverpa armigera (Hübner), que ainda não havia sido identificada no Brasil (Czepak et al., 2013), e que destruiu principalmente lavouras do oeste da Bahia, com perdas estimadas em mais de $\mathrm{R}$ \$ 1 bilhão. Tais perdas podem chegar a mais de $\mathrm{R} \$ 2$ bilhóes em todo o país, o que levou o governo brasileiro a decretar estado de emergência fitossanitária (REETZ et al., 2013). A entrada desta praga está provocando mudanças no manejo fitossanitário dos cultivos, com aplicaçóes mais frequentes de inseticidas que agravam a situação de desequilíbrio e trazem riscos de maior impacto na entomofauna benéfica.

Neste contexto, o objetivo do presente trabalho foi estudar a seletividade de inseticidas em favor dos inimigos naturais na cultura do algodão, bem como ampliar os conhecimentos sobre essa fauna benéfica nas condiçôes ecológicas do sudoeste da Bahia, visando à geração de subsídios que possam contribuir para o aperfeiçoamento de programas de manejo integrado de pragas.

\section{MATERIAIS E MÉTODOS}

O estudo foi desenvolvido na Fazenda Oliveira, localizada no município de Malhada, sudoeste da Bahia (altitude $433 \mathrm{~m}$, Latitude $14^{\circ} 16^{\prime} \mathrm{S}$ e Longitude $43^{\circ} 35^{\prime} \mathrm{W}$ ), no ano agrícola de 2010/2011.

O cultivar utilizado foi DeltaOpal, com semeadura mecânica com um trator Ford 5.610, acoplado com uma plantadeira Jumil de quatro linhas, realizada no dia 05 de novembro de 2010. Adotou-se o espaçamento de $0,75 \mathrm{~m}$ entre linhas, procedendo-se ao desbaste logo após a germinação, deixando cinco plantas por metro linear. $\mathrm{O}$ delineamento experimental utilizado foi o de blocos casualizados, com seis tratamentos e quatro repetiçóes, sendo cada parcela experimental constituída de nove linhas da cultura com $13 \mathrm{~m}$ de comprimento, compreendendo $87,8 \mathrm{~m}^{2}$. As cinco linhas centrais foram consideradas como úteis para efeito de avaliação. Foram selecionados produtos 
recomendados para a cultura e os mais utilizados na regiáo em estudo. Os tratamentos empregados foram: (1) Fipronil 200 SC (0,38 L.ha' $\left.{ }^{-1}\right)$; (2) Alfacipermetrina 100 SC (0,30 L.ha' ha $^{-1}$; (3) Lufenuron 50 CE (0,30 L.ha-1); (4) Imidacloprid 200 SC $\left(0,30\right.$ L.ha $\left.{ }^{-1}\right)$; (5) Paration Metil 600 CE (1,00 L.ha' $\left.{ }^{-1}\right)$; e (6) Testemunha (água). A aplicação dos produtos foi realizada 80 dias após a emergência das plantas (DAE), utilizando um pulverizador costal manual de pressáo constante $\left(\mathrm{CO}_{2}\right)$, munido de bicos XR 110 - 02, tipo jato plano (leque), operando com pressão de 2 bar, e com uma vazão de $200 \mathrm{~L}$ de calda por hectare. As caldas foram preparadas no dia da aplicaçấo e acondicionadas em garrafas PET devidamente identificadas. Ao final da aplicação de cada tratamento, o sistema era lavado. A aplicação foi realizada no período das $7 \mathrm{~h} 00$ às $10 \mathrm{~h} 00$, sendo iniciada com temperatura de $29,5^{\circ} \mathrm{C}$ e $51 \%$ de umidade relativa. Para evitar contaminação por deriva, procedeu-se à cobertura das duas parcelas próximas daquela que estava sendo pulverizada, utilizando-se lona plástica com a mesma dimensão das parcelas.

Foram realizadas quatro amostragens, uma um dia antes da aplicação (prévia) e três após a pulverização, no $1^{\circ}, 7^{\circ} \mathrm{e}$ $14^{\circ}$ dia após a aplicaçáo (DAA), utilizando-se os métodos de batida no pano para coleta de predadores e armadilha Moericke para himenópteros parasitoides. Em seguida, foram empregadas a metodologia descrita por Degrande et al. (2003) e a modificada de Perioto et al. (2002), respectivamente. Em cada parcela foram realizadas quatro batidas, envolvendo um total de 40 plantas. Artrópodes vivos e mortos caídos no pano foram coletados e acondicionados em potes plásticos, contendo álcool 70\%, e levados ao Laboratório de Entomologia da Universidade Estadual do Sudoeste da Bahia (UESB), campus de Vitória da Conquista, para triagem, contagem e identificação. Para coleta dos himenópteros parasitoides, foram distribuídas quatro armadilhas Moericke por parcela, em um total de 16 por tratamento, equidistantes 4 metros, colocadas rentes ao chão com $1 / 3$ de sua capacidade contendo água e detergente. As armadilhas permaneceram 48 horas no campo; após este período, o conteúdo da armadilha foi acondicionado em potes plásticos para posterior triagem. A transferência dos insetos das armadilhas para os potes plásticos era feita no campo com auxílio de pincel e peneira.

O complexo de inimigos naturais foi avaliado de maneira global, por meio da somatória dos indivíduos dos principais grupos ocorrentes, e os dados tabulados foram transformados em $\sqrt{X+0,5}$, sendo submetidos à análise de variância. As médias dos tratamentos foram comparadas pelo teste de Tukey a $5 \%$ de probabilidade. Foram calculadas as porcentagens de reduçáo das populaçóes dos inimigos naturais, utilizando-se a fórmula de Henderson; Tilton (1955). A classificação dos inseticidas testados quanto à toxicidade foi realizada segundo a escala da International Organization for Biological and Integrated Control of Noxious Animals and Plants (IOBC) (Boller et al., 2005), em função da redução da população dos inimigos naturais: a) inócuo ou levemente tóxico $(\mathrm{N})$ : 0 a 50\%; moderadamente tóxico (M): 51 a 75\%; e c) tóxico (T): acima de $75 \%$.

\section{RESULTADOS E DISCUSSÃO}

\section{Efeito dos inseticidas sobre predadores}

Aranhas (Arachnida: Araneae), formigas (Hymenoptera: Formicidae) e joaninhas (Coleoptera: Coccinellidae) foram os predadores de maior abundância capturados durante o período experimental. $\mathrm{Na}$ avaliação prévia, não foram verificadas diferenças significativas entre os tratamentos, indicando uniformidade da abundância dos grupos na área antes das aplicaçôes dos inseticidas, apesar de ter havido diferenças no número médio de aranhas entre o tratamento T3 (lufenuron) e os tratamentos T1 (fipronil) e T4 (imidacloprida), não diferindo, contudo, da testemunha (Tabela 1). No primeiro dia após a aplicação, houve um decréscimo bastante acentuado em termos absolutos no número médio dos predadores de todos os tratamentos com inseticidas, em relação à avaliaçấo

Tabela 1. Número médio de larvas, adultos e total de joaninhas, aranhas e formigas coletados na cultura do algodão, na avaliação prévia e no primeiro dia após a aplicação (DAA) de inseticidas. Malhada (BA), 2011.

\begin{tabular}{|c|c|c|c|c|c|c|c|c|c|c|}
\hline \multirow{2}{*}{ Tratamentos } & \multicolumn{5}{|c|}{ PRÉVIA } & \multicolumn{5}{|c|}{$10 \mathrm{DAA}$} \\
\hline & JL & JA & JT & AR & $\mathbf{F}$ & JL & JA & JT & AR & $\mathbf{F}$ \\
\hline T1 - Fipronil & $14,50 a$ & $8,25 a$ & $22,75 a$ & $16,50 \mathrm{~b}$ & $18,75 a$ & $0,50 a$ & $2,25 a$ & $2,75 a$ & $11, \mathrm{OObc}$ & $0,75 a$ \\
\hline T2 - Alfacpermetrina & $6,75 a$ & $5,50 a$ & $12,25 a$ & $22,50 a b$ & $13,75 a$ & $3,50 a$ & $6,00 a$ & $6,00 a$ & $14,75 b c$ & $8,00 a$ \\
\hline T3 - Lufenuron & $7,50 a$ & $5,25 a$ & $12,75 a$ & $28,75 a$ & $9,50 a$ & $2,25 a$ & $8,00 a$ & $10,25 a$ & $33,25 a$ & $14,25 a$ \\
\hline T4 - Imidacloprid & $5,50 a$ & $4,25 a$ & $9,75 a$ & $15,75 b$ & $12,25 a$ & $1,55 a$ & $3,25 a$ & $4,50 a$ & $16,50 a b c$ & $2,75 a$ \\
\hline T5 - Paration Metil & $3,50 a$ & $4,50 a$ & $8,00 a$ & $20,75 a b$ & $12,00 a$ & $3,25 a$ & $2,50 a$ & $5,75 a$ & $10,00 c$ & $0,25 a$ \\
\hline T6 - Testemunha & $3,75 a$ & $7,25 a$ & $11,00 a$ & $18,25 a b$ & 29,00a & $3,25 a$ & $5,75 a$ & $9,00 a$ & $25,75 a b$ & $12,75 a$ \\
\hline C. V. & 51,81 & 23,50 & 31,44 & 12,06 & 55,33 & 29,34 & 35,38 & 26,44 & 18,65 & 91,67 \\
\hline
\end{tabular}

Médias seguidas da mesma letra nas colunas não diferem estatisticamente pelo teste de Tukey, a $5 \%$ de probabilidade. Análise de variância realizada com dados transformados em raiz de $\sqrt{X+0,5}$.

JL: larvas; JA: adultos; JT: total de joaninhas; AR: aranhas; F: formigas. 
prévia e testemunha, exceto para aranhas no tratamento T3 (lufenuron) (Tabela 1). Nessa avaliação, efeitos negativos significativos dos inseticidas somente foram constatados para as aranhas, com maior impacto causado pelo tratamento T5 (paration metil), seguido do T1 (fipronil) e T2 (alfacipermetrina), embora estes dois últimos não tenham diferido da testemunha. Isso evidencia o impacto dos inseticidas sobre a entomofauna benéfica, principalmente os de ação de choque, como os piretroides e os organofosforados. Na avaliaçáo realizada aos sete dias, também só foram verificados efeitos significativos para o número médio de aranhas, sendo o tratamento T2 (alfacipermetrina) o que determinou maior impacto, seguido pelo fipronil (T1), embora este não tenha diferido da testemunha (Tabela 1). O fipronil pertence ao grupo químico fenil-pirazol, cujo modo de ação não segue o caminho bioquímico dos piretroides (bloqueadores do canal de sódio) e dos organofosforados e carbamatos (inibidores da acetilcolinesterase). O produto é neurotóxico também, porém, atua bloqueando a passagem de íons de cloro pelo canal regulado pelo ácido gama-aminobutírico (GABA), sendo ativo principalmente por ingestão (BOARETTO; ForTI, 1997). O fipronil demonstra toxicidade seletiva por possuir uma ligação mais forte aos canais de cloro dos insetos do que dos mamíferos, apresentando menor toxicidade aos vertebrados de modo geral (Coutinho et al., 2005; Gunasekara; Troung, 2007). $\mathrm{Na}$ avaliação do $14^{\circ}$ dia após aplicação, não houve diferença significativa entre os tratamentos, sendo observado um restabelecimento da abundância de predadores na área (Tabela 2).

Quanto à toxicidade, para joaninhas, ao considerar o total de larvas e adultos, constata-se que na primeira avaliaçáo o produto fipronil foi tóxico, e os demais, seletivos; na segunda avaliação, fipronil e imidacloprida foram medianamente tóxicos, sendo os demais seletivos (Tabela 3); e aos 14 dias, apenas o T5 (paration metil) foi moderamente tóxico, e os demais, seletivos (Tabela 4). No entanto, ao se considerar apenas larvas, em todo o experimento constata-se que estas foram mais sensíveis aos produtos do que os adultos. Na primeira avaliação, o tratamento T1 (fipronil) foi tóxico, e o T3 (lufenuron) e o T4 (imidacloprida) foram classificados como medianamente tóxicos a essa fase de desenvolvimento; enquanto isso, aos sete dias, fipronil (T1), lufenuron (T3) e imidacloprida (T4) mostraram-se tóxicos, e alfacipermetrina (T2), medianamente tóxico, sendo seletivo somente o paration metil (T5) (Tabela 3). Ainda para larvas de joaninhas, aos 14 dias os tratamentos $\mathrm{T} 1$ (fipronil), T2 (alfacipermetrina) e T5 (paration metil) foram classificados como medianamente tóxicos (Tabela 4). Esses resultados indicam a importância de se avaliar larvas e adultos, porque geralmente larvas de algumas espécies de joaninha sáo encontradas em maior abundância do que adultos, a exemplo do trabalho de COsTA et al. (2010), que demonstraram que joaninhas do gênero Scymnus foram as mais abundantes dentre os coccinelídeos, com maior quantidade de larvas desse grupo

Tabela 2. Número médio de larvas, adultos e total de joaninhas, aranhas e formigas coletados na cultura do algodão, no sétimo e décimo quarto dias após a aplicação (DAA) de inseticidas. Malhada (BA) 2011.

\begin{tabular}{|c|c|c|c|c|c|c|c|c|c|c|}
\hline \multirow{2}{*}{ Tratamentos } & \multicolumn{5}{|c|}{$7^{\circ}$ DAA } & \multicolumn{5}{|c|}{$14^{\circ} \mathrm{DAA}$} \\
\hline & JL & JA & JT & AR & $\mathbf{F}$ & JL & JA & JT & AR & $\mathbf{F}$ \\
\hline T1 - Fipronil & $2,50 a$ & $2,25 a$ & $4,75 a$ & $2,03 b c$ & $1,25 a$ & $7,75 a$ & $5,75 a$ & $13,50 a$ & $15,50 a$ & $2,00 a$ \\
\hline T2 - Alfacipermetrina & $4,25 a$ & $0,50 a$ & $4,75 a$ & $1,77 c$ & $2,00 a$ & $4,00 a$ & $3,50 a$ & $7,50 a$ & $10,50 a$ & $13,50 a$ \\
\hline T3 - Lufenuron & $2,75 a$ & $3,25 a$ & $6,00 a$ & $16,25 a$ & $10,75 a$ & $9,00 a$ & $5,50 a$ & $14,50 a$ & $15,75 a$ & $7,75 a$ \\
\hline T4 - Imidacloprid & $0,75 a$ & $1,50 a$ & $2,25 a$ & $14,25 a$ & $30,75 a$ & $4,75 a$ & $2,25 a$ & $7,00 a$ & $16,25 a$ & $20,00 a$ \\
\hline T5 - Paration Metil & $3,75 a$ & $4,25 a$ & $8,00 a$ & $11,25 a b$ & $17,25 a$ & $2,50 a$ & $1,00 a$ & $3,50 a$ & $11,75 a$ & $3,75 a$ \\
\hline T6 - Testemunha & $5,50 a$ & $2,00 a$ & $7,50 a$ & $11,50 a b$ & $24,25 a$ & $5,50 a$ & $5,25 a$ & $10,75 a$ & $21,50 a$ & $16,25 a$ \\
\hline C. V. & 55,49 & 31,92 & 46,65 & 20,48 & 68,88 & 36,53 & 30,27 & 30,98 & 19,47 & 65,14 \\
\hline
\end{tabular}

Médias seguidas da mesma letra nas colunas não diferem estatisticamente pelo teste de Tukey, a $5 \%$ de probabilidade.

Análise de variância realizada com dados transformados em raiz de $\sqrt{X+0,5}$.

JL: larvas; JA: adultos; JT: total de joaninhas; AR: aranhas; F: formigas.

Tabela 3. Porcentagem (\%) de redução das populações de larvas, adultos e total de joaninhas, aranhas e formigas na cultura do algodão, no primeiro e sétimo dias após a aplicação (DAA) de inseticidas. Malhada (BA), 2011.

\begin{tabular}{|c|c|c|c|c|c|c|c|c|c|c|}
\hline \multirow{2}{*}{ Tratamentos } & \multicolumn{5}{|c|}{$1^{\circ} \mathrm{DAA}$} & \multicolumn{5}{|c|}{$7^{\circ}$ DAA } \\
\hline & JL (\%) & JA (\%) & JT (\%) & AR (\%) & F (\%) & JL (\%) & JA (\%) & TJ (\%) & AR (\%) & F (\%) \\
\hline T1 - Fipronil & $96,02 \mathrm{~T}$ & $66,60 \mathrm{M}$ & $85,20 T$ & $33,00 \mathrm{~N}$ & $90,90 \mathrm{~T}$ & $88,24 \mathrm{~T}$ & $1,2 \mathrm{ON}$ & $69,38 M$ & $81,40 \mathrm{~T}$ & $92,03 \mathrm{~T}$ \\
\hline T2 - Alfacipermetrina & $40,17 \mathrm{~N}$ & $0,00 \mathrm{~N}$ & $40,14 N$ & $54,00 \mathrm{M}$ & $0,00 \mathrm{~N}$ & $57,10 \mathrm{M}$ & $67,05 \mathrm{M}$ & $43,13 N$ & $80,50 \mathrm{~T}$ & $82,60 T$ \\
\hline T3 - Lufenuron & $65,38 \mathrm{M}$ & $0,00 \mathrm{~N}$ & $1,74 \mathrm{~N}$ & $20,50 \mathrm{~N}$ & $0,00 N$ & $97,60 \mathrm{~T}$ & $0,00 \mathrm{~N}$ & $31,98 \mathrm{~N}$ & $10,30 \mathrm{~N}$ & $15, \mathrm{OON}$ \\
\hline T4 - Imidaclopid & $67,48 \mathrm{M}$ & $4, \mathrm{OON}$ & $43,60 \mathrm{~N}$ & $25,00 \mathrm{~N}$ & $48,94 \mathrm{~N}$ & $90,70 \mathrm{~T}$ & $0,00 \mathrm{~N}$ & $66,15 \mathrm{~N}$ & $0,00 \mathrm{~N}$ & $0,00 \mathrm{~N}$ \\
\hline T5 - Paration Metil & OO,OON & $30,00 \mathrm{~N}$ & $12,15 \mathrm{~N}$ & $66,00 M$ & $95,26 \mathrm{~T}$ & $27,00 \mathrm{~N}$ & $0,00 \mathrm{~N}$ & $0,00 N$ & $14,00 N$ & $0,00 \mathrm{~N}$ \\
\hline
\end{tabular}

Eficiência determinada segundo HENDERSON; TILTON (1955).

Classificação da seletividade segundo escala de Boller et al. (2005), onde:

$\mathrm{N}$ : inócuo ou levemente tóxico; M: moderadamente tóxico; T: tóxico. JL: larvas; JA: adultos; JT: total de joaninhas; AR: aranhas; F: formigas. 
Tabela 4. Porcentagem (\%) de redução das populações de larvas, adultos e total de joaninhas, aranhas e formigas coletados na cultura do algodão, no décimo quarto dia após a aplicação (DAA) de inseticidas. Malhada (BA), 2011.

\begin{tabular}{|c|c|c|c|c|c|c|}
\hline \multirow{2}{*}{ Tratamentos } & \multicolumn{6}{|c|}{$14^{\circ} \mathrm{DAA}$} \\
\hline & JL (\%) & JA (\%) & JT (\%) & AR (\%) & F (\%) & TG (\%) \\
\hline T1 - Fipronil & $63,56 \mathrm{M}$ & $3,75 \mathrm{~N}$ & $39,28 N$ & $20,26 \mathrm{~N}$ & $81,00 T$ & $33,10 \mathrm{~N}$ \\
\hline T2 - Alfacipermetrina & $59,60 M$ & $12,12 \mathrm{~N}$ & $37,35 \mathrm{~N}$ & $60,40 M$ & $0, \mathrm{OON}$ & $26,33 N$ \\
\hline T3 - Lufenuron & $18,18 \mathrm{~N}$ & O,OON & $0,00 \mathrm{~N}$ & $53,50 \mathrm{M}$ & O,OON & $16,00 \mathrm{~N}$ \\
\hline T4 - Imidaclopid & $41,12 \mathrm{~N}$ & $30,04 \mathrm{~N}$ & $26,54 \mathrm{~N}$ & $12,42 \mathrm{~N}$ & $0,00 N$ & $0,00 N$ \\
\hline T5 - Paration Metil & $51,56 \mathrm{M}$ & $69,31 \mathrm{M}$ & $55,23 \mathrm{M}$ & $52,00 \mathrm{M}$ & $44,23 N$ & $38,43 \mathrm{~N}$ \\
\hline
\end{tabular}

Eficiência determinada segundo HENDERSON ; TILTON (1955).

Classificação da seletividade segundo escala de BolLer et al. (2005), onde: N: inócuo ou levemente tóxico; M: moderadamente tóxico; T: tóxico.

JL: larvas; JA: adultos; JT: total de joaninhas; AR: aranhas; F: formigas.

de joaninhas e com predomínio de adultos de E. connexa. Quanto ao fipronil, os dados discordam daqueles apresentados por SOARES; Busoli (2000), cujos autores consideraram o produto seletivo às joaninhas (Coleoptera: Coccinelidae) Scymnus sp. e Cycloneda sanguinea (L., 1763).

Com relação às aranhas, os tratamentos T1 (fipronil), T2 (alfacipermetrina) e T5 (paration metil) foram medianamente tóxicos na primeira avaliação, e os demais, inócuos; na segunda avaliaçáo, apenas os tratamentos T1(fipronil) e T4 (imidacloprida) apresentaram-se como tóxicos (Tabela 3); enquanto isso, aos 14 dias, os tratamentos T1 (fipronil) e T4 (imidacloprida) foram inócuos, sendo os demais medianamente tóxicos (Tabela 4). Com relação aos piretroides, Suekane et al. (2011) verificaram efeitos prejudiciais de bifentrina e fenpropatrina a joaninhas do gênero Scymnus e a aranhas em cultivo de algodáo nas condiçóes de Dourados (MS), concordando em parte com os resultados do presente trabalho.

Quanto às formigas predadoras, o fipronil (T1) apresentou-se como tóxico em todas as avaliaçóes (Tabelas 3 e 4); a alfacipermetrina (T2) variou de inócua (primeira e terceira avaliação) a tóxica (segunda avaliação); o lufenuron (T3) e a imidacloprida (T4) foram classificados como inócuos em todas as avaliaçôes; e o paration metil (T5) foi classificado como tóxico na primeira avaliação e inócuo aos 7 e 14 dias da aplicação. Neste trabalho, a amostragem de formigas pela batida no pano, que implica em agitar as plantas vigorosamente para provocar a queda dos insetos no pano, pode náo ter sido representativa do agroecossistema estudado. Segundo Monteiro (2008), as formigas predadoras forrageiam principalmente no solo, e raramente nas plantas; ocorrem baixas taxas de ocupação de algodoeiros G. hirsutum por formigas (menos de $20 \%$ das plantas), o que inviabiliza o estabelecimento de conclusôes sobre a seletividade dos produtos estudados a esses insetos.

Os resultados indicam que o fipronil tem forte ação de choque, na formulação utilizada (líquida), sobre os grupos de predadores estudados. Apesar de ser um princípio ativo usado em iscas tóxicas para o controle de formigas cortadeiras, cujo princípio básico é a ação retardada por ingestâo
(BoARETTO; ForTi, 1997), inseticidas à base de fipronil têm sido recomendados para uso em pulverizaçóes nas culturas de algodão, arroz, cana-de-açúcar, milho e soja, assim como em sementes de arroz, cevada, soja, feijāo e na água para irrigação do arroz (Coutinho et al., 2005). O piretroide alfacipermetrina mostrou-se moderadamente tóxico às aranhas e moderadamente tóxico às formigas, sendo inócuo aos demais predadores, o que está parcialmente de acordo com alguns estudos registrados na literatura (FonseCA et al., 2007; OliveIra et al., 2008; SuEKANe et al., 2011). FonseCA et al. (2007) verificaram que a aplicaçáo de piretroide à base de lambdacialotrina resultou em redução de $43,8 \%$ das aranhas em cultivo de algodáo, com recolonização dos predadores 10 dias após a aplicação. No milho, a deltametrina não afetou o complexo de predadores da parte aérea das plantas (MicherefF Filho et al., 2002), mostrando toxicidade seletiva ao grupo de aranhas. $\mathrm{O}$ inseticida à base de imidacloprida foi seletivo às aranhas, concordando com os resultados obtidos por FonseCA et al. (2008). Quanto ao paration metil, os resultados discordam dos estudos realizados em algodáo por FonSECA et al. (2008), e em cultivo de arroz irrigado, por Oliveira et al. (2011). Nesses dois trabalhos, o paration metil foi considerado seletivo às aranhas.

\section{Comunidade de aranhas}

As aranhas dividem-se, normalmente, em três subordens: a) Mesothelae: caracterizadas por carácteres primitivos, sendo suas espécies exclusivas da região asiática; b) Mygalomorphae: popularmente conhecidas como caranguejeiras; e c) Araneomorphae: aranhas verdadeiras, que englobam cerca de $90 \%$ das aranhas conhecidas. A maioria das aranhas é noturna e ocupa muitos ambientes naturais e cultivados (AQuino et al., 2007).

Foram coletadas 994 aranhas, distribuídas em 13 famílias, destacando-se Thomisidae, com 60,36\%, e Araneidae, com $11,97 \%$, como as mais abundantes, totalizando $72,33 \%$ do total (Tabela 5). Na avaliaçấo prévia, foram constatadas 10 famílias e, após a aplicação de inseticidas, a diversidade subiu para 11 famílias, permanecendo assim até os 14 dias após a aplicaçấo. Não foram encontrados representantes das famílias Licosidae, Pholcidae e Sparassidae na avaliação prévia, as 
Tabela 5. Número e porcentagem (\%) de aranhas coletadas na batida do pano na cultura do algodão, em função das famílias. Malhada (BA), 2011.

\begin{tabular}{|c|c|c|c|c|c|c|}
\hline Família & $\begin{array}{c}\text { Prévia } \\
\left(\mathrm{N}^{\circ}\right)\end{array}$ & $\begin{array}{c}10 \text { DAA } \\
\left(N^{\circ}\right)\end{array}$ & $\begin{array}{c}7^{\circ} \text { DAA } \\
\left(N^{\circ}\right)\end{array}$ & $\begin{array}{c}14^{\circ} \text { DAA } \\
\left(\mathrm{N}^{\circ}\right)\end{array}$ & $\begin{array}{l}\text { Total } \\
\left(\mathrm{N}^{\circ}\right)\end{array}$ & $\%$ \\
\hline Anyphaenidae & 24 & 27 & 7 & 21 & 79 & 7,95 \\
\hline Araneidae & 35 & 28 & 25 & 31 & 119 & 11,97 \\
\hline Corinnidae & 1 & 1 & 1 & 1 & 4 & 0,40 \\
\hline Lycosidade & 0 & 0 & 0 & 1 & 1 & 0,10 \\
\hline Linyphiidae & 7 & 9 & 2 & 2 & 20 & 2,01 \\
\hline Miturgidae & 13 & 4 & 0 & 8 & 25 & 2,52 \\
\hline Oxyopidae & 8 & 12 & 11 & 4 & 35 & 3,52 \\
\hline Philodromidae & 20 & 26 & 6 & 10 & 62 & 6,24 \\
\hline Pholcidae & 0 & 0 & 1 & 0 & 1 & 0,10 \\
\hline Salticidae & 4 & 8 & 1 & 3 & 16 & 1,61 \\
\hline Sparassidae & 0 & 1 & 2 & 0 & 3 & 0,30 \\
\hline Theridiidae & 5 & 18 & 1 & 5 & 29 & 2,92 \\
\hline Thomisidae & 205 & 148 & 96 & 151 & 600 & 60,36 \\
\hline TOTAL & 322 & 282 & 153 & 237 & 994 & 100 \\
\hline$\%$ & 32,40 & 28,37 & 15,40 & 23,84 & 100 & 100 \\
\hline Total de Famílias & 10 & 11 & 11 & 11 & & \\
\hline
\end{tabular}

quais apareceram, contudo, em baixo número nas avaliaçóes após as aplicaçóes.

Segundo Eкschmitт et al. (1997, apud Aquino et al., 2007), existem certos agroecossistemas mais favoráveis à utilização das aranhas no controle biológico em relação a outros, como os sistemas orgânicos, plantio direto, culturas perenes e policultivos. Para esses autores, o cultivo anual com araçáo e gradagem promove perturbação contínua no habitat das aranhas, afetando negativamente sua abundância e efetividade no controle biológico. Por outro lado, Rinaldi; Ruiz (2002) relataram que levantamentos de aranhas em áreas agrícolas têm revelado alta diversidade desses artrópodes, fato que discorda da ideia de que os sistemas agrícolas são simplificados quanto à araneofauna. Os dados obtidos sobre as aranhas neste trabalho foram relativamente similares, em termos de diversidade de famílias, aos resultados de levantamentos desse grupo de predadores em outros ambientes, tanto naturais como agroecossistemas. Em seis tipos de ambientes diferenciados pelo manejo e vegetação, RiNALDi; ForTi (1997) coletaram um total de 12 famílias de aranhas, variando de 3 a 12 nos diferentes ambientes, sendo as menores diversidades nas áreas agrícolas (sete famílias em cana-de-açúcar e três em pastagem). Em cultivo de cana-de-açúcar, no estado de São Paulo, Rinaldi et al. (2002) coletaram 1.291 espécimes de aranhas distribuídas em 20 famílias, sendo Theridiidae, Salticidae, Anyphaenidae e Aranaeidae as mais abundantes. Os autores ressaltaram que, apesar das condições climáticas adversas, dos tratamentos químicos, dos distúrbios agrícolas, do solo descoberto e, especialmente, das queimadas periódicas, o agroecossistema de cana-de-açúcar tem uma fauna de aranhas bastante diversa. A comunidade de aranhas para um mesmo cultivo em diferentes regióes produtoras de seringueira, no estado de São Paulo, variou, sendo maior nas regiōes de Cedral e Taquaritinga do que em Pindoramalias, com
19, 19 e 17 famílias, respectivamente. As famílias Anyphaenidae, Salticidae, Theridiidae e Corinnidae foram as mais abundantes nos três cultivos (RINALdi; RuIz, 2002). Situação semelhante ocorreu em manchas de cerrado, sendo encontrados números diferenciados de famílias em função do município amostrado, sendo 12 em São Carlos, 18 em Pirassununga e 16 em Luís Antônio (Rinaldi; Trinca, 2008). Segundo Marc et al. (1999, apud AQUiNo et al., 2007), as aranhas são amplamente diversas, apresentando diferentes grupos funcionais em relação às estratégias de predação, modo de dispersão e grande habilidade para resistir às condiçóes ecológicas adversas.

\section{Efeito dos inseticidas sobre himenópteros parasitoides}

$\mathrm{Na}$ avaliação prévia, não houve diferença significativa entre tratamentos, demonstrando uniformidade da área experimental em relação aos parasitoides (Tabela 6). Não foi possível realizar as análises de variância após a aplicação dos inseticidas pelo fato de ter ocorrido, em termos absolutos, uma redução bastante acentuada da população de parasitoides no primeiro e no sétimo dia após a aplicação dos inseticidas, com sinais de recuperação no $14^{\mathrm{a}}$ dia. Busoli et al. (2007) relataram que os agentes de controle biológico natural, como os parasitoides, têm suas ações reduzidas por fatores abióticos, bióticos e pelo uso indiscriminado de inseticidas, provocando vácuo biótico, quando avaliaram o parasitismo natural em lagartas de Trichoplusia ni em algodoeiro no centro-oeste do Brasil.

Quanto à porcentagem de mortalidade dos himenópteros parasitoides (Tabela 7), observa-se que, no primeiro dia após a aplicação, todos os tratamentos foram seletivos, com mortalidade inferior a 38\%. Aos sete dias, o lufenuron (T3) não apresentou seletividade para os parasitoides, causando $100 \%$ de 
Tabela 6. Número médio de parasitoides coletados na cultura do algodão, nas avaliações prévias e no $1^{\circ}, 7^{\circ}$ e $14^{\circ}$ dias após a aplicação (DAA) de inseticidas. Malhada (BA), 2011.

\begin{tabular}{|c|c|c|c|c|}
\hline Tratamentos & $\begin{array}{l}\text { Prévia* } \\
\left(\mathrm{N}^{\circ}\right)\end{array}$ & $\begin{array}{c}1^{\circ} \mathrm{DAA}^{* *} \\
\left(\mathrm{~N}^{\circ}\right)\end{array}$ & $\begin{array}{c}7 \circ \mathrm{DAA}^{* *} \\
\left(\mathrm{~N}^{\circ}\right)\end{array}$ & $\begin{array}{c}14^{\circ} \mathrm{DAA}^{* *} \\
\left(\mathrm{~N}^{\circ}\right)\end{array}$ \\
\hline T1 - Fipronil & $10,25 a$ & 0,75 & 0,50 & 3,25 \\
\hline T2 - Alfacipermetrina & $07,25 a$ & 1,75 & 0,50 & 3,50 \\
\hline T3 - Lufenuron & $08,75 a$ & 1,00 & 0,00 & 4,50 \\
\hline T4 - Imidacloprid & $06,75 a$ & 0,75 & 1,00 & 3,25 \\
\hline T5 - Paration Metil & 08,50a & 0,50 & 0,25 & 3,00 \\
\hline T6 - Testemunha & 08,00a & 0,75 & 0,75 & 3,25 \\
\hline
\end{tabular}

Médias seguidas da mesma letra nas colunas não diferem estatisticamente pelo teste de Tukey, a 5\% de probabilidade. *Análise de variância realizada com dados transformados em $\sqrt{X+0,5}$. **Análise de variância não realizada.

Tabela 7. Porcentagem (\%) de redução das populações de himenópteros parasitoides na cultura do algodão coletados no $1^{\circ}, 7^{\circ}$ e $14^{\circ}$ dias após a aplicação (DAA) de inseticidas. Malhada (BA), 2011.

\begin{tabular}{|c|c|c|c|}
\hline Tratamentos & $\begin{array}{c}\text { 10 DAA } \\
\text { (\%) }\end{array}$ & $\begin{array}{c}\text { 7० DAA } \\
(\%)\end{array}$ & $\begin{array}{c}14^{\circ} \text { DAA } \\
(\%)\end{array}$ \\
\hline T1 - Fipronil & $21,95 \mathrm{~N}$ & $47,97 \mathrm{~N}$ & $21,95 \mathrm{~N}$ \\
\hline T2 - Alfacipermetrina & O,OON & $26,44 N$ & O,OON \\
\hline T3 - Lufenuron & O,OON & $100,00 T$ & $0, \mathrm{OON}$ \\
\hline T4 - Imidacloprid & $0, \mathrm{OON}$ & $0,00 \mathrm{~N}$ & $0,00 \mathrm{~N}$ \\
\hline T5 - Paration Metil & $37,25 \mathrm{~N}$ & $68,63 \mathrm{M}$ & $13,13 \mathrm{~N}$ \\
\hline
\end{tabular}

Eficiência determinada segundo HENDERSON; TILTON (1955).

Classificação da seletividade segundo escala de Boller et al. (2005), onde:

$\mathrm{N}$ : inócuo ou levemente tóxico; M: moderadamente tóxico; T: tóxico. mortalidade, enquanto os tratamentos T1 (fipronil), T2 (alfacipermetrina) e T4 (imidacloprida) foram seletivos. O paration metil (T5), que foi seletivo no primeiro dia após a aplicação, apresentou-se moderadamente tóxico no sétimo dia, reduzindo a população de parasitoides em $68,63 \%$. Na avaliação do $14^{\circ}$ dia após aplicaçáo dos inseticidas, todos os tratamentos apresentaram seletividade para o complexo de parasitoides em estudo, com mortalidade inferior a 22\%. De modo geral, verificou-se reduçáo bastante acentuada da população de parasitoides após a aplicação dos inseticidas, inclusive na testemunha. Pode-se levantar a hipótese de que devido à alta capacidade de dispersão destes insetos, o tamanho da parcela tenha sido menor do que o desejável para esse tipo de estudo, ocorrendo dispersão entre parcelas não tratadas (total de quatro) e tratadas (total de 20), o que levaria, então, à mortalidade dos indivíduos, independentemente dos tratamentos. Estes dados indicam a necessidade de estudos sobre o tamanho da parcela adequada para pesquisa sobre seletividade de parasitoides em campo, dificultando a obtenção de conclusóes no presente trabalho sobre a seletividade dos produtos aos parasitoides.

\section{Comunidade de himenópteros parasitoides}

Foram coletadas 322 espécimes, distribuídas em 18 famílias (Tabela 8), número bem próximo àquele encontrado por Perioto et al. (2002), de 22 famílias, em cultivo de algodão

Tabela 8. Número e porcentagem (\%) de himenópteros parasitoides coletados em armadilha Moericke, na cultura do algodão, em função da família e épocas de avaliação. Malhada (BA), 2011.

\begin{tabular}{|c|c|c|c|c|c|c|}
\hline Família & $\begin{array}{l}\text { Prévia } \\
\left(\mathrm{N}^{\circ}\right)\end{array}$ & $\begin{array}{c}1^{\circ} \text { DAA } \\
\left(\mathrm{N}^{\circ}\right)\end{array}$ & $\begin{array}{l}7^{\circ 0} \text { DAA } \\
\left(N^{\circ}\right)\end{array}$ & $\begin{array}{c}14^{\circ} \text { DAA } \\
\left(\mathrm{N}^{\circ}\right)\end{array}$ & $\begin{array}{l}\text { Total } \\
\left(\mathrm{N}^{\circ}\right)\end{array}$ & $\%$ \\
\hline Bethylidae & 4 & 0 & 0 & 0 & 4 & 1,24 \\
\hline Braconidae & 9 & 1 & 0 & 2 & 12 & 3,73 \\
\hline Ceraphronidae & 7 & 2 & 1 & 12 & 22 & 6,83 \\
\hline Chalcididae & 15 & 0 & 0 & 0 & 15 & 4,66 \\
\hline Diapriidae & 7 & 4 & 0 & 3 & 14 & 4,35 \\
\hline Encyrtidae & 3 & 0 & 0 & 6 & 9 & 2,80 \\
\hline Eulophidae & 17 & 3 & 2 & 6 & 28 & 8,70 \\
\hline Eurytomidae & 1 & 1 & 0 & 0 & 2 & 0,62 \\
\hline Evanniidae & 0 & 0 & 2 & 0 & 2 & 0,62 \\
\hline Figitidae & 53 & 5 & 0 & 9 & 67 & 20,81 \\
\hline Ichneumonidae & 26 & 3 & 2 & 2 & 33 & 10,25 \\
\hline Megaspilidae & 1 & 0 & 0 & 1 & 2 & 0,62 \\
\hline Mymaridae & 13 & 2 & 2 & 8 & 25 & 7,76 \\
\hline Platygastridae & 3 & 0 & 0 & 1 & 4 & 1,24 \\
\hline Pteromalidae & 2 & 0 & 0 & 3 & 5 & 1,55 \\
\hline Scelionidae & 38 & 0 & 2 & 21 & 61 & 18,95 \\
\hline Signiphoridae & 1 & 0 & 0 & 0 & 1 & 0,31 \\
\hline Trichogrammatidae & 5 & 1 & 0 & 10 & 16 & 4,97 \\
\hline TOTAL & 205 & 22 & 11 & 84 & 322 & 100 \\
\hline$\%$ & 63,66 & 6,83 & 3,42 & 26,09 & & 100 \\
\hline Total de Famílias & 17 & 9 & 6 & 13 & 18 & \\
\hline
\end{tabular}


no município de Ribeirão Preto (SP). Destacaram-se as famílias Figitidae (20,81\%), Scelionidae (18,95\%), Ichneumonidae $(10,25 \%)$ e Eulophidae $(8,70)$ como as mais frequentes, totalizando 58,71\% do total (Tabela 6). Dos 322 indivíduos, 205 foram coletados na avaliação prévia, respondendo por $64,0 \%$; 22 indivíduos, no primeiro dia após a aplicação, correspondendo a 7\%; e 11 individuos, ou 3,5\%, no sétimo dia. No $14^{\circ}$ dia foram coletados 84 indivíduos, respondendo por $26 \%$ do total.

Observou-se reduçáo bastante acentuada das populaçôes dos parasitoides após as aplicaçóes dos inseticidas, com sinais de recuperação ao $14^{\circ}$ dia. Perioto et al. (2002) estudaram a diversidade de himenópteros parasitoides na cultura do algodáo, no município de Ribeirão Preto (SP), e também, observaram que, após a aplicação de inseticidas na área, ocorreu uma drástica redução de himenópteros parasitoides, apresentando sinais de recuperação de suas populaçốes na amostragem realizada oito dias após a aplicação dos tratamentos. As famílias Bethylidae, Chalcididae e Signiphoridae desapareceram após a aplicação dos produtos, enquanto representantes de Eurytomidae não foram coletados a partir do sétimo dia após a aplicaçáo. Famílias de grande importância para o controle biológico das pragas do algodoeiro foram encontradas na área experimental, como Braconidae, Icheneumonidae, Eulophidae, Figitidae e Pteromalidae, o que corrobora citaçóes de Gravena; Cunha (1991), Fernandes et al., (1999) e Evangelista JúNior et al., (2006) que também relataram a ocorrência de espécies dessas famílias atuando como inimigos naturais de pragas dessa cultura.

\section{CONCLUSÕES}

A toxicidade dos produtos varia em funçáo do grupo de inimigo natural. A Imidacloprida é seletiva às aranhas, sendo os demais inseticidas medianamente tóxicos (alfacipermetrina e paration metil: $1^{\circ}$ e $14^{\circ} \mathrm{DAA}$; lufenuron: $14^{\circ} \mathrm{DAA}$ ) ou tóxicos (fipronil e alfacipermetrina: $\left.7^{\circ} \mathrm{DAA}\right)$. O fipronil (10 DAA), a alfacipermetrina (7 $\mathrm{DAA})$ e o paration metil (14\% $\mathrm{DAA})$ são medianamente tóxicos aos adultos de joaninhas.

Nenhum inseticida estudado é seletivo às larvas de joaninhas, sendo os maiores impactos ocasionados até os sete dias após a aplicação, com exceção do paration metil, classificado como inócuo até esse período. Registra-se a ocorrência de 13 famílias de aranhas em agroecossistema de algodáo na regiáo de Malhada (BA), sendo Thomisidae e Aranaeidae as mais abundantes. Registra-se a ocorrência de 18 famílias de himenópteros parasitoides em agroecossistema de algodão na região de Malhada (BA), sendo Figitidae, Scelionidae, Ichneumonidae e Eulophidae as mais frequentes.

\section{AGRADECIMENTOS}

Aos biólogos, Profa. Isabela Maria Piovesan Rinaldi, Douglas Donizeti de Souza e Juliana de Oliveira Pacchi do Instituto de Biociências da Unesp-Campus de Botucatu, SP, pela identificação das aranhas.

| | | | | | | | | | | | | | | | | | | | | | | | | | | | | | | | | | | | | | | | | | | | | | | | | | | | | | | | | | | | | | | | | | | | | | | | | | | | | | | | | | | | | | | | | | | | | | | | | | | | | | | | | | | | | | | | | | | | | | | | | | | | | | | | | | | | | | | | | | | | | | | | | | | | | | | | | | | | | | | | | | | | | | | | | | | | | | | | | | | | | | | | | | | | | | | | | | | | | | | | | | | | | | | | | | | | | | | | | | | |

\section{REFERÊNCIAS}

ALVES, A.P.; SERIKAWA, R,H. Controle químico de pragas do algodoeiro. Revista Brasileira de Oleaginosas e Fibrosas, Campina Grande, v.10, n.3, p.1197-1209, 2006.

AQUINO, A.M.; CORREIA, M.E.F.; AGUIAR-MENEZES, E.L. Aranhas em agroecossistemas. Seropédica: Embrapa Agrobiologia, (Documentos 230 / Embrapa Agrobiologia), 2007. 16p.

BOARETTO, M.A.C.; FORTI, L.C. Perspectivas no controle de formigas cortadeiras. Série Técnica IPEF, Botucatu, SP, v. 11 , n.30, p.31-46, 1997.

BOLLER, E.F.; VOGT, H.; TERNES, P.; MALAVOLTA, C. Working document on selectivity of pesticides. International Organization for Biological and Integrated Control of Noxious Animals and Plants. Disponível em: <http://www.iobc.ch/2005/ Working\%Document\%20Pesticides_Explanations.pdf. Acesso em: 6 abr. 2011.

BUSOLI, A.C. Práticas culturais, regulador de crescimento, controle químico e feromônio no manejo integrado de pragas do algodão. p. 29-52. In: DEGRANDE, P.E. O bicudo do algodoeiro. Campo Grande: UFMS, 1991.141p.

BUSOLI, A.C.; SILVA, E.A.; PESSOA, R.; NAIS, J.; ARAÚJO, C.R. Parasitismo natural de lagartas de Trichoplusia ni em algodoeiro no centro Oeste do Brasil. In: CONGRESSO BRASILEIRO DE ALGODÃO, VI, 2007, Uberlândia, MG. Resumos. Uberlândia: 2007. p.1-4.

CAMPOS, A.R.; GRAVENA, S.; BERTOZO, R.; BARBIERI, J. Artrópodes predadores na cultura algodoeira e comparação de métodos de amostragem. Anais da Sociedade Entomológica do Brasil, Porto Alegre, v.15, p.5-20, 1986.

COSTA, L.L; MARTINS, I.C.F.; BUSOLI, A.C.; CIVIDANES, F.J. Diversidade e abundância de artrópodes predadores associados a diferentes cultivares de algodoeiro. Pesquisa Agropecuária Tropica, Goiânia, v.40, n.4, p.483-490, 2010.

COUTINHO, C.F.B.; TANIMOTO, S.T.; GALLI, A.; GARBELLINI, G.; TAKAYAMA, M.; AMARAL, R.B..; MAZO, L.H.; AVACA, L.A.; MACHADO, S.A.S. Pesticidas: mecanismo de ação, degradação e toxidez. Pesticidas: Revista de Ecotoxicologia e Meio Ambiente, Curitiba, v. 15, p.65-72, 2005.

CROCOMO, W.B. (ed.). Manejo integrado de pragas. Botucatu: Editora Universidade Estadual Paulista, 1990. 358p.

CZEPAK, C.; ALBERNAZ, K.C.; VIVIAN, L.M.; GUIMARÃES, H.O.; CARVALHAIS, T. Primeiro registro de ocorrência de Helicoverpa armigera (Hübner) (Lepidoptera: Noctuidae) no Brasil. Pesquisa Agropecuária Tropical, Goiânia, v.43, n.1, p.110-113, 2013. 
CZEPAK, C.; FERNANDES, P.M.; ALBERNAZ, K.C.; RODRIGUES, O.D.; SILVA, L.M.; SILVA, E.A.; TAKATSUKA, F.S.; BORGES, J.D. Seletividade de inseticidas ao complexo de inimigos naturais na cultura do algodão (Gossypium hirsutum L.). Pesquisa Agropecuária Tropical, Goiânia, v.35, n.2, p.123-127, 2005.

DEGRANDE, P.E.; OLIVEIRA, M.A.; RIBEIRO, J.F.; BARROS, R.; NOGUEIRA, R.F.; RODRIGUES, A.L.L.; FERNANDES, M.G. Avaliação de métodos para quantificar predadores de pragas do algodoeiro. Arquivos do Instituto Biológico, São Paulo, v.70, n.3, p.291-294, 2003.

DEGRANDE, P.E. Manejo integrado de pragas do algodoeiro. In: EMBRAPA. Centro de Pesquisa Agropecuária do Oeste (Dourados-MS). Algodão: Informações técnicas. Dourados: EMBRAPA-CPAO; Campina Grande: EMBRAPA-CNPA, 1998. 267p. (Circular Técnica 7). p. 154-191.

EVANGELISTA JÚNIOR, W.S.; ZANUNCIO JÚNIOR, J.S.; ZANUNCIO, J.C. Controle biológico de artrópodes do algodoeiro com predadores e parasitóides. Revista Brasileira de Oleaginosas e Fibrosas, Campina Grande, v.10, n.3, p.1147-1 165, 2006.

FERNANDES M.G.; BUSOLI, A.C.; DEGRANDE, P.E. Parasitismo Natural de Ovos de Alabama argillacea Hüb. e Heliothisvirescens Fab. (Lep.: Noctuidae) por Trichogramma pretiosum Riley (Hym.: Trichogrammatidae) em Algodoeiros no Mato Grosso do Sul. Anais Sociedade Entomológica do Brasil, Porto Alegre,v.28, n.4, p.695-701, 1999.

FONSECA, P.R.B.; NOGUEIRA, F.R.; LOPES, J.; FERNANDES, M.G.; DEGRANDE, P.E. Impacto de aplicação de Lambdacialotrina sobre inimigos naturais de pragas de algodoeiro e período de recolonização de predadores. Revista Brasileira de Agrociência, Pelotas, v.13, n.3, p.409-412, 2007.

FONSECA, P.R.B. da; BERTONCELLO, T.F.; RIBEIRO, J.F.; FERNANDES, M.G.; DEGRANDE, P.E. Seletividade de inseticidas aos inimigos naturais ocorrentes sobre o solo cultivado com algodoeiro. Pesquisa Agropecuária Tropical, Goiânia, v.38, n.4, p.304-309, 2008.

GRAVENA, S.; CUNHA, H.F. Artrópodos predadores na cultura algodoeira. Jaboticabal: FUNEP, 1991.41p.

GUNASEKARA, A.S.; TROUNG, T. Environmental fate of fipronil. California Environmental Protection Agency Sacramento, 2007. 28p.

HENDERSON, C.F.; TILTON, E.W. Tests with acaricides against the brown wheat mite. Journal Economic Entomology, v.48, n.2. p.157-161, 1955.

LIMA JUNIOR, I.S.; NOGUEIRA, R.F.; BERTONCELLO, T.F.; MELO, E.P.; SUEKANE, R.; DEGRANDE, P.E. Seletividade de inseticidas sobre o complexo de predadores das pragas do algodoeiro. Pesquisa Agropecuária Tropical, Goiânia, v.40, n.3, p.347-353, 2010.

MICHEREFF FILHO, M.; DELLA LUCIA, T.M.C.; CRUZ, I.; GALVÃO, J.C.C.; VEIGA, C.E. Impacto de deltametrina em artrópodes-pragas e predadores na cultura do milho. Revista Brasileira de Milho e Sorgo, Sete Lagoas, v.1, n. 1, p.25-32, 2002.

MONTEIRO, A.F.M. Diversidade de Formigas (Hymenoptera: Formicidae) em Sistemas de Cultivo de Algodoeiro no Distrito Federal.
2008. 86f. Dissertação (Mestrado em Ecologia) - Universidade de Brasília, Brasília, 2008.

NUNES, J.C.S.; SILVA, A.L.; VELOSO, V.R.S.; SANTOS, S.V.; SANTOS, S.P.. Seletividade de inseticidas aos predadores das pragas do algodoeiro. Pesquisa agropecuária tropical, v.29, n.1, p.71-75, 1999 .

OLIVEIRA, J.V.; FREITAS, T.F.S.; FIUZA, L.M.; MENEZES, V.G.; FRITZ, L.L.; ANDREIS, T.F. Estudo da seletividade de inseticidas na população de aranhas em arroz irrigado. Disponível em: http:// www.irga.rs.gov.br/uploads/anexos/4.4.4-estudo.pdf. Acesso em: 8 jun. 2011.

PERIOTO, N.W.; LARA, R.I.R.; SANTOS, J.C.C.; SELEGATTO, A. Seletividade de alguns inseticidas utilizados na cultura do algodoeiro (Gossypium hirsutum L.) a himenópteros (Insecta, Hymenoptera). Arquivos do Instituto Biológico, São Paulo, v.68, 2001. (suplemento).

PERIOTO, N.W.; LARA, R.I.R.; SANTOS, J.C.C.; SELEGATTO, A. Himenópteros parasitóides (Insecta, Himenóptera) coletados em cultura de algodão (Gossypium hirsutum L.) (Malvácea) no município de Ribeirão Preto, SP, Brasil. Revista Brasileira de Entomologia, v.46, n.2, p.165-168, 2002.

REETZ, E.R.; KIST, B.B.; SANTOS, C.E.; CARVALHO, C.; POLL, H. Anuário Brasileiro do Algodão 2013. Santa Cruz do Sul: Editora Gazeta, Santa Cruz, 2013. 144p.

RINALDI, I.M.P.; FORTI, L.C. Hunting spiders of woodland fragments and agricultural habitats in the atlantic rain forest region Brazil. Studies on Neotropical Fauna and Environment, v.32, p.244255, 1997.

RINALDI, I.M.P.; TRINCA, L.A. Spider assemblages in widelyseparate patches of cerrado in São Paulo State, Brazil. Acta Biologica Paranaense, Curitiba, v.37, n.3,4, p.165-180, 2008.

RINALDI, I.M.P.; MENDES, B.P.; CADY, A.B. Distribuition and importance of spiders inhabiting a Brazilian sugar cane plantation, Revista Brasileira Zoologia, v.19, p.271-279, 2002. Suplemento 1.

RINALDI, I.M.P.; RUIZ, G.R.S. Comunidade de aranhas (Araneae) em cultivos de seringueira (Hevea brasiliensis Muell. Arg.) no Estado de São Paulo. Revista Brasileira de Zoologia, v.19, v.3, p.781-788. 2002.

SILVA, C.A.D.; ALMEIDA, R.P. Manejo integrado de pragas do algodoeiro no Brasil. Campina Grande: EMBRAPA-CNPA, 1998, circular técnica $27,65 p$.

SOARES, J.J.; BUSOLI, A.C. Efeito de inseticidas em insetos predadores em culturas de algodão. Pesquisa Agropecuária Brasileira, v.35, n.9. p.1889-1894, 2000.

SUEKANE, R.; DEGRANDE, P.E.; LIMA JUNIOR, I.S.; KODAMA, C.; KODAMA, E. Seletividade de acaricidas aos predadores Scymnus SP. (Coleoptera: Coccinelidae) e Araneae (Arachnida) em algodoeiro (Gossypium hirsutum L.) sob condições de campo. Pesticidas: Revista de Ecotoxicologia e Meio Ambiente, Curitiba, v.21, p.25-38, 2011. 